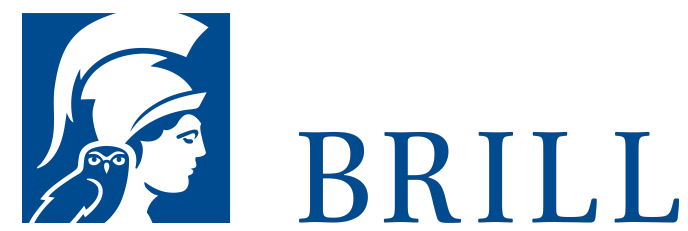

\title{
So tun, als ob
}

Analyse eines ungewöhnlichen Begriffs mit einer Anwendung auf die Theorien der Fiktionalität

Author: Laura Mercolli

Was haben Lügen, Plagiieren, Schauspielern und Tagträumen gemeinsam? Ihnen allen liegt ein So-Tun-als-ob zugrunde. Der vielschichtige Begriff des So-Tuns-als-ob wird in diesem Buch einer eingehenden Analyse unterzogen, wobei in taxonomischer Weise verschiedene Arten von So-Tun-als-ob identifiziert werden. So-Tun-als-ob spielt nicht nur im Alltag, sondern auch in den aktuellen fiktionalitätstheoretischen Diskussionen eine wichtige Rolle. Eine Vielzahl von Theorien zieht den Begriff heran, um verschiedene Phänomene zu erklären, z.B. fiktionale Rede, Rede über Fiktion oder negative Existenzaussagen. In der vorliegenden Studie wird anhand der erarbeiteten Begriffsanalyse von So-Tun-als-ob gezeigt, dass einerseits diese Inanspruchnahme des Begriffs auf keiner einheitlichen Auffassung von So-Tun-als-ob basiert und dass andererseits seine Schlüsselrolle in den fiktionalitätstheoretischen Debatten nur bedingt gerechtfertigt ist. Da der Begriff des So-Tuns-als-ob auch in anderen Disziplinen zum Begriffsinventar gehört, sind die Ergebnisse interdisziplinär in der Entwicklungspsychologie, den Kognitionswissenschaften, der Literatur- und Kunsttheorie anwendbar.

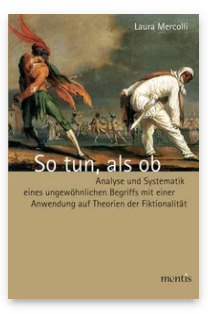

Pages: 212

Seiten

Language:

German

Subjects:

General,

Philosophy

Publisher: Brill | mentis

E-Book (PDF)

Released online:

14 Feb 2012

ISBN: $978-3^{-}$

89785-941-8

List price

USD $\$ 52.00$

Paperback

Publication date:

14 Feb 2012

ISBN: 978-3-

89785-761-2

List price

USD $\$ 52.00$ 
For more information see brill.com

Order information: Order online at brill.com +44330 333 0049 | customerservices@brill.com Submission information: brill.com/authors

Titles published by Brill | Fink, Brill | mentis or Brill | Schöningh: +49(o)715413279216| brill@brocom.de 